\title{
EL CONTROL INMEDIATO DE LEGALIDAD EN EL MARCO DEL ESTADO DE EMERGENCIA ECONÓMICA, SOCIAL Y ECOLÓGICA
}

\section{Immediate control of legality within the framework of a state of economic, social and ecological emergency}

Carlos Alberto Almanza Agámez ${ }^{1}$

Uriel Ángel Pérez Márquez ${ }^{2}$

Recibido: 17 de abril de 2020 - Aceptado: 02 de junio de 2020

\section{RESUMEN}

La pandemia Covid-19, trajo como consecuencia un cambio sustancial en la forma de crear el derecho, de aplicar las normas y de garantizar los derechos de la sociedad. Con la declaratoria de un estado de excepción, concretamente en el estado de emergencia económica, social y ecológica por parte del Ejecutivo, se configura una fluctuación en el equilibrio del ejercicio del poder público. Por consiguiente, este artículo pretende revisar y analizar que el ordenamiento jurídico colombiano, contempla un saludable control en cabeza del juez de lo contencioso administrativo, logrando con esto, que, aunque exista una procedencia incluso oficiosa del control inmediato de legalidad, permite que la seguridad jurídica siga prevaleciendo.

Palabras clave: Calamidad pública; urgencia manifiesta; estado de excepción; emergencia económica.

\begin{abstract}
The Covid-19 pandemic brought as a consequence a substantial change in the way of creating the law, applying the rules and guaranteeing the rights of society. With the declaration of a state of exception, specifically in the state of economic, social and ecological emergency by the Executive, a fluctuation in the balance of the exercise of public power is configured. Therefore, this article aims to review and analyze that the Colombian legal system contemplates a healthy control in the head of the judge of the administrative contentious, achieving with this, that although there is an even unofficial provenance of immediate control of legality, allows legal security continue to prevail.
\end{abstract}

\footnotetext{
${ }^{1}$ Abogado, Especialista en Estudios Político Económicos de la Universidad del Norte, Especialista en Derecho Administrativo de la Universidad Libre Seccional Cartagena, Maestrante en Derecho - Énfasis en Investigación de la Universidad del Norte. Docente Universitario e Investigador. Decano de la Facultad de Ciencias Sociales y Humanas de la Corporación Universitaria Rafael Núñez. ORCID: https://orcid.org/0000-0002-5990-8289 E-mail: Carlos.almanza@ curnvirtual.edu.co

${ }^{2}$ Abogado consultor y Conjuez del Tribunal Administrativo de Bolívar. Especialista en Derecho Contentencioso Administrativo (universidad Externado de Colombia) y en Contratación Estatal (Universidad de Medellín). Magister (C) en Contratación Estatal (universidad de Medellín). Docente Universitario de pregrado y postgrado de Corporación Universitaria Rafael Núñez, Universidad Tecnológica de Bolívar, Universidad de San Buenaventura, Universidad del Sinú y Universidad del Magdalena, ESAP). Orcid: https://orcid.org/0000-0002-8393-3476 E-mail: Uriel.perez@curnvirtual.edu.co
} 
Keywords: Public calamity, manifest urgency, state of emergency, economic emergency.

\section{INTRODUCCIÓN}

La posibilidad que tiene el ejecutivo para adoptar medidas urgentes en el marco de situaciones calamitosas está estrechamente vinculada al sistema presidencialista de gobierno. Se trata de permitir que el Gobierno Nacional pueda responder desde la institucionalidad a situaciones que desbordan los criterios de normalidad, sin violentar el orden jurídico existente.

Desde la reforma constitucional de 1968 se introdujo, en el artículo 122 Superior, la figura del estado de emergencia económica, social y calamidad pública (Estado de emergencia), dejando el artículo 121 para casos de guerra exterior y conmoción interior o estado de sitio. (Constitución Política de Colombia, 1968)

En la Constitución de 1991 se plasmó la conclusión a la que arribó la Asamblea Nacional Constituyente acerca del abuso o uso excesivo que se había hecho de las figuras de los estados de excepción, principalmente del estado de sitio en el que vivió el país por más de 40 años, casi de forma ininterrumpida, aunque ciertamente se ratificó la necesidad de dotar al presidente de poderes especiales para aquellos casos en los que no son suficientes las atribuciones ordinarias, por lo que se aprobaron y consagraron los artículos 212, 213 y 215 (estado de guerra exterior, conmoción interior y emergencia, respectivamente). (Constitución Política de Colombia, 1991)

Con la ley estatutaria No. 137 (1994) se regularon las facultades atribuidas al Gobierno durante dichos estados, indicando que las mismas sólo podrán ser utilizadas "cuando circunstancias extraordinarias hagan imposible el mantenimiento de la normalidad mediante los poderes ordinarios del Estado". También se fijan los controles al ejercicio de dichas facultades extraordinarias y las garantías para proteger los derechos humanos de conformidad con los tratados internacionales, al tenor del artículo 2.

\subsection{La emergencia declarada por el Gobierno nacional con ocasión de la pandemia COVID-19}

Con el Decreto No. 417 de 17 de marzo (2020) el señor presidente de la República, junto a sus ministros, declaró el estado de emergencia económica, social y ecológica en todo el territorio nacional. Hubo una segunda declaratoria por treinta días más, mediante el decreto legislativo 637 de 06 de mayo (2020).

Se basó esta declaratoria en el anuncio de pandemia hecho por la Organización Mundial de la Salud -OMS- del 11 de marzo (2020) y en la declaratoria de estado de emergencia sanitaria en todo el país por parte del Ministerio de Salud, mediante la Resolución No. 385 del 12 de Marzo (2020), con el propósito de facilitar el aislamiento social y tomar medidas que garanticen la contención del virus, dada la detección de un incremento representativo en los casos de contagio y en el altísimo riesgo de propagación, lo que se traduce en la puesta en riesgo de toda la población colombiana. En esta resolución se establecieron dos frentes, uno de salud pública y, otro, de orden económico, que se verían afectados con el 
COVID-19, concluyendo que "la salud, el empleo, el abastecimiento de bienes básicos, la economía y el bienestar de todos los habitantes del territorio nacional" se comprometerían de manera importante por lo que, de acuerdo con el Gobierno, se requerían medidas INMEDIATAS y URGENTES que no podían adoptar con las atribuciones ordinarias.

En estas circunstancias el ejecutivo, dotado de estas facultades extraordinarias, adopta medidas y toma decisiones y legisla transitoriamente. Sin embargo, esos poderes tienen como límite la sujeción al ordenamiento jurídico superior y esto se patentiza en el control expedito y en tiempo real que la jurisdicción de lo contencioso administrativo ejerce sobre tales decisiones, mediante el medio de control consignado en el artículo 136 de la ley 1437 (2011), conocida como Código de procedimiento administrativo y de lo contencioso administrativo o CPACA.

\section{Metodología}

La presente investigación tiene un método descriptivo y documental bibliográfico. Es descriptiva porque busca exponer los fundamentos teóricos y jurisprudenciales del control inmediato de legalidad. Es documental pues se realiza apoyándose en fuentes de carácter documental. Es del carácter especial de las bibliográficas pues su objeto de estudio está en la jurisprudencia, obras jurídicas de distinta índole, que recogen los supuestos y planteamientos respecto al control inmediato de legalidad de las decisiones adoptadas en el estado de emergencia económica, social y ecológica.

\section{Desarrollo del Tema}

En este acápite el estudio se centrará en revisar (i) los presupuestos de procedencia general o común a las declaratorias de emergencia, (ii) se abordará el estado de emergencia económica, social y ecológica, propiamente dicho y, finalmente, se revisarán (iii) los aspectos relacionados con el control judicial de los actos administrativos que se profieran en el marco de la declaratoria de emergencia, enfatizando en temas que habitualmente son sometidos a esta clase de control, es decir, algunas de las decisiones más recurrentes tomadas por la administración en casos de emergencia.

\subsection{Presupuestos de procedencia para la declaratoria de una emergencia}

La declaratoria de un estado de emergencia es una prerrogativa que tiene el presidente de la república, es un poder excepcional, que se materializa mediante un decreto legislativo, que, a su vez, le permite expedir decretos legislativos contentivos de órdenes y decisiones tendientes a mitigar los efectos negativos de la situación de urgencia por la que se está atravesando. La vigencia de estos decretos va más allá de la declaratoria de emergencia; rigen hasta que el congreso los modifique o derogue, menos en los casos que traten sobre nuevos tributos, que rigen hasta la siguiente vigencia fiscal, salvo que el congreso los deje como permanentes al siguiente año.

El punto de partida fáctico es fundamental a la hora de declarar una emergencia. Se trata de hechos sobrevinientes y extraordinarios que alteren el orden económico, social o ecológico y que además difieran de los constitutivos de guerra exterior o conmoción interior. Para la Corte Constitucional estos hechos deben ser reales e imprevisibles, que demandan una respuesta inminente por parte del Estado (Corte Constitucional, 2015). 
Como ilustración se trae a cuento el decreto 4975 (2009), mediante el cual, el ejecutivo declaró el estado de emergencia social, aduciendo la necesidad de utilizar adecuadamente los recursos del sistema de salud. Con base en esta declaratoria se expidieron muchos decretos que incluían la creación de un IVA especial a las cervezas, sanciones a los médicos que ordenaran tratamientos especializados, entre otros.

La honorable Corte Constitucional (2010), en el control que hizo a la declaratoria de la emergencia, estimó que no se cumplía con el requisito de imprevisibilidad, ya que el gobierno disponía de mecanismos ordinarios que servían para afrontar la situación en el corto plazo; también llamó la atención del legislador para que cumpliera con su trabajo.

La imprevisibilidad se predica del brote de la pandemia, para el caso del Covid-19, tal como se advirtió en la primera parte de este documento, que amerita la adopción de medidas de contingencia y mitigación del riesgo. Se recuerda que la Ley Estatutaria No. 137 de junio 2 (1994) (que regula los Estados de Excepción en Colombia) estipula que en las medidas encaminadas a conjurar la emergencia deben mediar los principios de necesidad y proporcionalidad, a través, por ejemplo, del fortalecimiento al sistema de salud.

Las condiciones de anormalidad que trastocan el funcionamiento natural de la administración deben ser afrontadas con medidas de urgencia transitorias, tal como se encuentra reglamentado en los artículos 212 a 215 de la Carta Política, donde se limita temporalmente la declaratoria del estado de emergencia, a noventa días máximo, para el caso de la emergencia económica, social y ecológica (Constitución Política, artículo 215).

\subsection{Declaratoria de emergencia económica, social y ecológica}

El artículo 215 de la Carta Política colombiana, hace especial énfasis en la necesidad de satisfacer el presupuesto objetivo de procedencia, esto es, la ocurrencia de un hecho que perturbe o amenace con perturbar en forma grave e inminente el orden económico o una gran calamidad pública (Quinche, 2018).

Los decretos que se profieran deben referirse a materias que tengan relación directa y específica con el estado de excepción. A diferencia de lo que sucede con los decretos expedidos en el estado de conmoción interior, los que se producen en estado de emergencia económica, social y ecológica, pueden reformar o derogar la legislación pre existente y tienen vigencia indefinida, hasta tanto el legislador los derogue o reforme, exceptuando la normatividad que tenga que ver con la imposición o modificación de tributos (Corte constitucional, 1994).

El gobierno, por lo general, canaliza la producción normativa de los estados de excepción, mediante la utilización de dos figuras jurídicas que dotan de mayor versatilidad el actuar administrativo, sobre todo en materia de compra pública, arista que, dicho sea de paso, es de las que más se ve trastocada por ser esta la forma, a través del cual se robustece la capacidad de respuesta y se adquieren los bienes, productos y servicios necesarios para contener la amenaza. 
Carlos Alberto Almanza Agámez y Uriel Ángel Pérez Márquez

\subsubsection{De la declaratoria de calamidad y de la urgencia manifiesta}

Apenas necesario resulta traer a colación la conceptualización normativa y procedimiento de declaratoria que trae la Ley No. 1523 del 24 de abril (2012) -que adopta la política nacional de gestión del riesgo de desastres y establece el Sistema Nacional de Gestión del Riesgo de Desastres-, a partir de su artículo 57. Es pertinente, además, en esta ocasión revisar la reglamentación de la declaratoria de urgencia manifiesta como causal de contratación directa, al tenor de lo dispuesto en el artículo 42 de la Ley 80 (1993), toda vez que, como se indicó líneas arriba, la mayoría de los actos administrativos que se expiden tienen que ver con contratación estatal, bajo la causal de contratación directa.

Se alude, entonces, a un evento o episodio traumático, derivado de causas naturales o técnicas, que altera gravemente el orden económico, social o ecológico y que ocurre de manera imprevista y sobreviniente (Corte Constitucional, 2017). También señaló la Corte que los acontecimientos no solo deben tener una entidad propia de alcances e intensidad traumáticas, que logren conmocionar o trastocar el orden económico, social o ecológico, lo cual caracteriza su gravedad, sino que, además, deben constituir una ocurrencia imprevista, y por ello diferentes a los que se producen regular y cotidianamente, esto es, sobrevinientes a las situaciones que normalmente se presentan en el discurrir de la actividad de la sociedad, en sus diferentes manifestaciones y a las cuales debe dar respuesta el Estado mediante la utilización de sus competencias normales.

En el caso de la declaratoria de la urgencia manifiesta para efectos de la contratación estatal, se tiene que está regulado en normas ordinarias, por demás, esto es, el artículo 42 de la Ley 80 de 1993 y el numeral 4 del artículo 2 de la Ley 1150 (2007). Esto se traduce en el hecho que el legislador ha sido lo suficientemente previsivo y logra diseñar de forma previa un procedimiento o reglas de juego para situaciones "anormales".

Para el caso del covid-19, se tiene que artículo 7 del Decreto Legislativo No. 440 de 20 de marzo (2020) dispone lo siguiente:

“... la declaratoria de estado de emergencia económica, social y ecológica, y en los términos del artículo 42 de la Ley 80 de 1993, se entiende comprobado el hecho que da lugar a declarar la urgencia manifiesta por parte de las entidades estatales, para la contratación directa del suministro de bienes, la prestación de servicios o la ejecución de obras en el inmediato futuro, con el objetivo de prevenir, contener y mitigar los efectos de la Pandemia del coronavirus COVID-19, así como para realizar las labores necesarias para optimizar el flujo de los recursos al interior del sistema de salud. Las actuaciones contractuales adelantadas con fundamento en la urgencia manifiesta se regirán por la normatividad vigente. Con el mismo propósito, las entidades excluidas de la Ley 80 de 1993 podrán contratar de manera directa esta clase de bienes y servicios...”.

Lo anterior quiere decir que, al menos en principio, la posibilidad de reorientar los recursos permitidos por la ley para optimizar el sistema de salud autorizado. El control que ejerce el juez de lo contencioso administrativo versa, entre otros, sobre este aspecto, precisamente, tal como se analizará en el siguiente apartado. 


\subsection{Control judicial en el marco de un estado de emergencia}

Los poderes de la administración no se extienden por fuera del derecho, ni siquiera en la más calamitosa de las circunstancias. Las medidas son tomadas bajo el control del Juez que verifica que se han reunido correctamente tres elementos: una situación realmente excepcional, de tal manera que la aplicación integral del derecho positivo normal no pueda haber sido razonablemente contemplada; un interés público suficientemente poderoso como para justificar el abandono de ciertas reglas tales como la continuidad del funcionamiento de los servicios públicos, el ejercicio de ciertas libertades, finalmente, la imposibilidad para la administración de actuar si permanece en el marco de la estricta legalidad.

Además, el juez administrativo se interroga respecto de si los poderes de los que se dotó la administración son necesarios y adaptados al objetivo por alcanzar, lo cual lo conduce a aceptar la validez de ciertos actos y a anular otros en las mismas circunstancias excepcionales.

El control que se ejerce sobre la normatividad producida en el marco del estado de emergencia es de los llamados controles objetivos de legalidad (Garzón, 2019), dentro de los que se encuentran la nulidad por inconstitucionalidad (artículo 135 del CPACA), nulidad simple (artículo 137 del CPACA), nulidad de cartas de naturaleza y de las resoluciones de autorización de inscripción (artículo 147 del CPACA), control por vía de excepción de los actos administrativos (artículo 148 del CPACA) y, obviamente, el control inmediato de legalidad de los actos administrativos proferidos en desarrollo de decretos legislativos.

Constituye este último, un mecanismo de restablecimiento del equilibrio de poderes que inevitablemente se ve alterado con la asunción de extraordinarias potestades por parte del Ejecutivo, nada menos que la de legislar, por ejemplo; pero también la de suspender leyes e imponer restricciones al ejercicio de algunos derechos ciudadanos.

El medio de control inmediato de legalidad está estrechamente ligado a la protección de la tutela judicial efectiva en el marco del estado de emergencia por la enfermedad Covid-19.

La tutela judicial efectiva es el derecho que tienen todas las personas a un recurso efectivo ante los jueces o tribunales competentes, y constituye uno de los pilares básicos del Estado de derecho en una sociedad democrática (Consejo de estado, 2016). Ese derecho tiene fundamento en los artículos 8 (sobre garantías procesales) y 25.1 (protección judicial) de la Convención Americana de los Derechos Humanos.

Respecto de lo anterior, en la sentencia del 29 de septiembre (1999) proferida por la Corte Interamericana de DDHH, en el caso Cesti Hurtado contra Perú, dicha Corporación señaló que, para que los Estados respeten ese derecho, no basta con que los recursos existan formalmente, sino que, además, deben tener efectividad real.

La Constitución Política de Colombia (1991) también consagra el derecho fundamental a una tutela judicial efectiva, lo cual se deduce de los artículos 1, 2, 29 y 229 de la Carta. Al 
respecto, la Corte Constitucional ha considerado que el derecho de acceder a la administración de justicia fija un deber de asegurar que los medios judiciales sean efectivos para resolver las controversias planteadas por todas las personas y que este:

Les impone a las autoridades públicas, como titulares del poder coercitivo del Estado y garante de todos los derechos ciudadanos, la obligación correlativa de promover e impulsar las condiciones para que el acceso de los particulares a dicho servicio público sea real y efectivo (Corte Constitucional, 2012)

Lo que significa, a su vez, el compromiso estatal de lograr, en forma real y no meramente nominal, que a través de las actuaciones judiciales se restablezca el orden jurídico y se protejan las garantías personales que se estiman violadas (Corte Constitucional, 2014).

De acuerdo con esto, se acoge lo desarrollado por el Consejo de Estado cuando considera que desde el punto de vista convencional y constitucional, el medio de control inmediato de legalidad definido en los artículos 20 de la Ley Estatutaria No. 137 de (1994) y artículo 136 del CPACA tiene como esencia el derecho a la tutela judicial efectiva, y ante la situación excepcional y extraordinaria generada en los estados de emergencia, como el propiciado por la pandemia de la covid-19, es posible extender el control judicial a todas aquellas medidas de carácter general dictadas en ejercicio de la función administrativa que no solo se deriven de los Decretos Legislativos emitidos por el Gobierno Nacional.

Esto significa que los actos generales emanados de las autoridades administrativas que tengan relación directa o indirecta con las medidas necesarias para superar el Estado de Emergencia, aunque también pudieran fundamentarse en las competencias definidas en el ordenamiento en condiciones de normalidad, dadas las circunstancias excepcionales, puede suceder que se presente la confluencia de propósitos y la superposición de competencias, lo cual autoriza al juez del control inmediato que avoque el conocimiento con el fin de garantizar la tutela judicial efectiva.

\subsubsection{Alcance del control de legalidad}

Este control es de carácter inmediato y su revisión puede tener lugar por remisión del acto que haga la autoridad administrativa a la autoridad judicial para que esta decida sobre su legalidad o, en su defecto, de oficio, siendo necesario aprehender su conocimiento de manera inmediata, en caso de incumplimiento del deber de remisión de la administración.

Un análisis del control inmediato de legalidad de las disposiciones dictadas en el marco de un estado de excepción, como el de emergencia, exige identificar las distintas clases de "medidas de carácter general" que se profieren en virtud del ejercicio de la función administrativa; es decir, definir el bloque de legalidad interno a partir del cual se ejerce dicho control. En ese orden, se observa que existen normas derivadas de la potestad reglamentaria, actos administrativos de carácter general y actos derivados de la potestad instructiva. (Consejo de Estado, 2020)

En cuanto a la potestad reglamentaria (Sánchez, 2020), conviene precisar que la Constitución Política de 1991 abandonó el sistema concentrado de potestad reglamentaria 
a instancias del Presidente de la República, e inauguró un sistema difuso o "policéntrico" (se reconoce en forma expresa, la potestad reglamentaria de diversos órganos constitucionales, como garantía de su autonomía y en materias indisponibles para otra clase de normas.) que recayó en diferentes órganos constitucionales, a quienes se les confirió también por vía constitucional de manera restringida competencias normativas en materias específicas; en otras palabras, con ocasión de la Constitución de 1991, la potestad reglamentaria no es exclusiva del Presidente de la República, cuestión diferente es que a este, por su condición de suprema autoridad administrativa del Estado, le corresponda por regla general esa atribución. Por tanto, lo anterior conduce a precisar que la Constitución.

"Consagró un 'sistema difuso' de producción normativa general o actos administrativos de efectos generales de carácter reglamentario, lo que significó, sin lugar a duda, un cambio fundamental respecto del ordenamiento superior consignado en la Carta de 1886”. (Corte Constitucional, 2014)

Dichas facultades especiales de reglamentación encuentran su fundamento en la autonomía reconocida por la Constitución Política a ciertas autoridades, y están limitadas, materialmente, por el mandato constitucional a cuyo desarrollo están obligados, como formalmente, por las condiciones impuestas para su ejercicio. Con todo, pese a que la Constitución Política es la fuente jurídica de toda potestad reglamentaria, también se ha señalado de tiempo atrás que el Congreso de la República puede atribuir la potestad reglamentaria por vía legal a organismos y autoridades distintos al presidente, en los casos en los cuales "sólo así es posible garantizar la efectividad de la norma jurídica que produce el legislador". (Consejo de Estado, 2016)

La potestad de expedir actos administrativos generales se relaciona con la expresión inherente de la administración de proferir actos unilaterales encaminados a producir efectos jurídicos y se forma por la concurrencia de elementos de tipo subjetivo (órgano competente), objetivo (presupuestos de hecho a partir de un contenido en el que se identifique objeto, causa, motivo y finalidad, y elementos esenciales referidos a la efectiva expresión de una voluntad unilateral emitida en ejercicio de la función administrativa) y formal (procedimiento de expedición).

Finalmente, la administración, en virtud del artículo 41 de la Ley 489 (1998), también ejerce la potestad instructiva, actos de carácter informal (directivas, circulares, instructivos, etc.) que ayudan a desarrollar de manera alternativa la función administrativa y cuyos efectos se proyectan únicamente en el ámbito interno de la administración con el objetivo de orientar, instruir o informar a los ciudadanos sobre el principio de legalidad; no obstante, dichos actos pueden impactar de igual forma en el bloque de legalidad, por lo que en estos eventos resulta procedente el control inmediato.

En línea con lo anterior, se contempla la posibilidad de solicitar la anulación de las manifestaciones de la actividad administrativa. Siendo esto así, es claro que el sometimiento de la administración pública al control puede recaer sobre manifestaciones formales -expresión de la potestad reglamentaria y actos administrativos generales-e informales - expresión de la potestad instructiva-. 
En el ordenamiento jurídico colombiano, la potestad reglamentaria no distingue entre decretos, actos administrativos generales, resoluciones y reglamentos, y aunque los tres primeros se consideran la materialización del poder reglamentario, mientras que a los reglamentos se los relaciona como manifestaciones de la organización del servicio público, su distinción, en la práctica, no es muy clara; pero, es posible afirmar que los decretos, actos administrativos generales y resoluciones son disposiciones administrativas generales y abstractas cuyos efectos son ad extra, mientras que los reglamentos tienen un efecto de auto organización ad intra.

El juez, en tanto custodio de la legalidad y constitucionalidad de la actividad administrativa, ejerce un control integral sobre todas las manifestaciones de la función administrativa, porque verifica que las manifestaciones de la administración sean consonantes con los requisitos formales y materiales señalados por los preceptos constitucionales y legales.

Ahora bien, cuando los artículos 20 de la Ley 137 de (1994) y 136 del CPACA hacen alusión al control judicial de las "medidas de carácter general", no se están refiriendo a todas las manifestaciones formales e informales de la actividad administrativa que se profieren en tiempos de normalidad, sino que el control inmediato de legalidad previsto en esas disposiciones y ejercido por la jurisdicción de lo contencioso administrativo recae en disposiciones que, en tiempos de excepción, reúnen dos presupuestos: i) subjetivo (autoridad que lo expide), que el acto formal o informal sea expedido por una autoridad del nivel nacional o territorial; y ii) objetivo (situación fáctica en la que se establezca objeto, causa, motivo y finalidad), que el acto sea general, se expida en ejercicio de la función administrativa y en desarrollo de los decretos legislativos durante el estado de excepción.

\subsubsection{Características esenciales del medio de control inmediato de legalidad}

Para este acápite se revisará ampliamente el reciente pronunciamiento del Consejo de Estado, bajo radicado No.11001-03-15-000-2020-01006-00, de 15 de abril (2020), con ponencia del Dr. William Hernández, de la Sección Segunda, Subsección A. En este auto interlocutorio se rechaza un control de legalidad inmediato hecho sobre un memorando del Ministerio de Relaciones Exteriores.

Se insiste en que el control inmediato de legalidad se constituye como una limitación al poder de las autoridades administrativas y es una medida eficaz para impedir la aplicación de normas ilegales en el marco de los estados de excepción. (Corte Constitucional, 1994)

Con apoyo en lo indicado por la Sala Plena de lo Contencioso Administrativo, se pueden compendiar las características esenciales de este medio de control de la siguiente manera:

1.- Recae sobre las medidas de carácter general que sean dictadas en ejercicio de la función administrativa (esto es, aquella que no es formalmente legislativa ni judicial, y además se encuentra vinculada directamente con la consecución de los intereses públicos) que se adopten en desarrollo de los Estados de Excepción.

2.- Si se trata de medidas de carácter general emitidas por autoridades nacionales, la competencia es del Consejo de Estado, y si se trata de actos proferidos por autoridades territoriales, es de los respectivos Tribunales Administrativos. 
3.- Para que se lleve a cabo el control inmediato no es necesario que el acto juzgado haya sido publicado, basta con su expedición.

4.- No es necesario que alguien ejerza el derecho de acción, toda vez que el medio de control tiene carácter automático e inmediato. Por ello, es obligación de la autoridad administrativa que profiere la medida de carácter general, enviarla en un plazo de 48 horas a partir de su expedición, y si no lo hace, la Jurisdicción de lo Contencioso Administrativo puede asumir su control oficioso.

5.- Aunque el control se ejerce de manera inmediata y automática, la medida de carácter general en ejercicio de la función administrativa continúa produciendo sus efectos, mientras no sea suspendida a través de una medida cautelar de urgencia o declarada su nulidad.

6.- Se trata de un control integral en cuanto debe hacerse sobre el fondo y la forma de la medida revisada. Por lo tanto, su juzgamiento deberá realizarse frente a cualquier norma que le sea superior y no solamente respecto del decreto legislativo en el cual se fundamenta. Igualmente, ha de tenerse en cuenta que el juicio sobre estas medidas no solo es de constitucionalidad y de legalidad, también es de razonabilidad. En ese sentido debe aplicarse el test de proporcionalidad para determinar si ella es acorde con el objetivo de la emergencia, y si además existen otras menos lesivas para los derechos y libertades de las personas.

7.- No obstante que el decreto legislativo con fundamento en el cual se expidió la medida de carácter general, hubiere sido declarado inexequible por la Corte Constitucional, la jurisdicción de lo contencioso administrativo debe ejercer el control inmediato que le asigna la ley, con el fin de establecer la legalidad de la medida durante el tiempo que produjo sus efectos.

8.- La sentencia que decide el medio de control inmediato de legalidad tiene el carácter de cosa juzgada relativa, porque dado su carácter oficioso, no implica el análisis de todos los posibles motivos de contradicción de la medida de carácter general con las normas que le son superiores $\mathrm{y}$, por ello, en el futuro puede ser demandada por cualquier persona en ejercicio de los medios ordinarios como la nulidad simple, con la salvedad de que los reproches deben versar sobre cuestiones distintas a las que se analizaron en el control automático. (Consejo de Estado, 2010)

9.- Finalmente, respecto de la pertinencia de las medidas cautelares de urgencia, tiene máxima importancia resaltar la necesidad del control inmediato, como lo indica el artículo 185 del CPACA, que regula el procedimiento a seguir por la Jurisdicción de lo Contencioso Administrativo con el fin de evitar la generación de situaciones administrativas que requieran de una corrección posterior y que pudieron evitarse de haberse contado con la decisión judicial de manera oportuna (Safar, 2015).

No obstante, los términos regulados en el artículo 185 del CPACA no enaltecen la celeridad esperada porque suman 65 días, lo cual contradice el sentido común de los términos máximos previstos en el artículo 215 de la Constitución Política, el cual indica que la declaratoria del Estado de Emergencia de orden económico, social, ecológico y grave calamidad pública, podrá ser decretado por periodos hasta de treinta días en cada caso, que sumados no podrán exceder de 90 días en el año calendario. 
Carlos Alberto Almanza Agámez y Uriel Ángel Pérez Márquez

Por esta razón, ante la evidente posibilidad de un tardío control de legalidad, el juez puede considerar que, en algunos casos, sea pertinente adoptar una medida cautelar de urgencia, tal y como lo autoriza el artículo 234 del CPACA. Cualquier ciudadano podrá presentar la solicitud dentro del término de diez días de fijación del aviso indicado en el numeral 2 del artículo 185 del CPACA. Incluso el juez en un caso evidente podrá decretar la medida cautelar de oficio, lo cual significa que se trata de una interesante excepción a la regla general de petición de parte cuando se trata de medidas cautelares, con el fin de garantizar la tutela judicial efectiva.

\section{CONCLUSIONES}

La estructura del estado colombiano está diseñada para mantener un equilibrio entre las ramas del poder, como prenda de garantía de no repetición de los errores de pasado y evitar la tiranía. Sin embargo, el devenir social y jurídico, precipitado por la desafortunada aparición de la pandemia conocida como covid-19, ha sacudido las bases mismas de los ordenamientos jurídicos a nivel mundial.

Las necesidades producto de la calamidad desbordan la capacidad de respuesta de la administración, abriendo la posibilidad de que ésta sea revestida transitoriamente de poderes excepcionales, sobre todo en el manejo de los recursos públicos.

Es por ello que todas las decisiones adoptadas en el marco de la declaratoria de una emergencia deben pasar por el crisol del juez, ya que se corre permanentemente el riesgo de que la solución pueda llegar a ser más nociva que la misma enfermedad.

Los gobernantes adoptan medidas, tales como la suspensión de todos los contratos estatales celebrados, vía decreto o la destinación de recursos para obras que no están relacionadas directamente con la situación calamitosa que se pretende apaciguar, entre otros muchos casos que, de no haber sido sometidos al control inmediato de legalidad, implicarían un exceso en el ejercicio del poder.

En todos los casos, las reflexiones desde un punto de vista estrictamente jurídico se hacen desde el tamiz del artículo 228 Superior en el sentido de que la "administración de justicia es función pública; que sus decisiones son independientes y que en ellas debe prevalecer el derecho sustancial".

En suma, no todas las decisiones adoptadas por el Ejecutivo en el marco de un estado de excepción, principalmente el de emergencia, se compadecen con el ordenamiento jurídico aplicable y, en tal virtud, deben ser declarados nulos por el juez de lo contencioso administrativo; para ello es fundamental el diseño expedito que tiene el medio de control analizado, pese a sus evidentes debilidades propias del sistema judicial.

\section{REFERENCIAS BIBLIOGRÁFICAS}

Congreso de la República de Colombia. (2011, 18 de enero). Ley 1437 de 2011. Código de Procedimiento administrativo y de lo contencioso administrativo (CPACA). Diario oficial $n^{\circ} 47.956$. 
Congreso de la República de Colombia. (1994, 3 de junio). Ley 137 de 1994. Diario oficial $\mathrm{n}^{\circ} 41.379$.

Congreso de la República de Colombia. (2011, 12 de julio). Ley 1474 de 2011. Diario oficial $n^{\circ} 48.128$.

Congreso de la República de Colombia. (2012, 24 de abril). Ley 1523 de 2012. Diario oficial nº 48.411 .

Congreso de la República de Colombia. (1993, 28 de octubre). Ley 80 de 1993. Diario oficial no41.094.

Congreso de la República de Colombia. (1998, 30 de diciembre). Ley 489 de 1998. Diario oficial no43.464.

Congreso de la República de Colombia. (1968, 11 de diciembre). Ley 489 de 1998. Diario oficial $n^{\circ} 43.464$.

Congreso de la República de Colombia. (2007, 16 de julio). Acto legislativo 1 de 1968, Por el cual se reforma la Constitución Política de Colombia.

Corte Interamericana de Derecho Humanos. Sentencia del 29 de septiembre de 1999, Caso Cesti Hurtado Vs. Perú. [presidente: Antonio A. Cançado Trindade del 29 de septiembre de 1999]

Consejo de Estado. Sala de lo contencioso administrativo, sección segunda, subsección A. Sentencia 2020-01006 del 15 de abril del 2020. [M.P William Hernández Gómez del 15 de abril de 2020]

Consejo de Estado. Sala Plena de lo contencioso administrativo. Sentencia 201100316/1210-11 del 9 de agosto del 2016 [M.P William Hernández Gómez del 9 de agosto de 2020]

Corte Constitucional. Sala Plena. Sentencia C-670 del 28 de octubre de 2015 [M.P María Victoria Correa del 28 de octubre de 2015]

Corte Constitucional. Sala Plena. Sentencia C-252 del 1 de abril de 2010. [M.P Jorge Iván Palacio del 16 de abril de 2010]

Corte Constitucional. Sala Plena. Sentencia C-466 del 19 de julio de 2017. [M.P Carlos Bernal Pulido del 19 de julio de 2017]

Corte Constitucional. Sala Plena. Sentencia C-426 del 29 de mayo de 2002. [M.P Rodrigo Escobar Gil del 29 de mayo de 2002]

Corte Constitucional. Sentencia C-500 del 16 de julio de 2014. [M.P Mauricio González Cuervo del 16 de julio de 1014] 
Carlos Alberto Almanza Agámez y Uriel Ángel Pérez Márquez

Corte Constitucional. Sentencia C-179 del 13 de abril de 1994. [M.P Carlos Gaviria Díaz del 1 de abril de 1994]

Corte Constitucional. Sentencia C-810 del 5 de noviembre de 2014. [M.P Mauricio González Cuervo del 5 de noviembre de 2014]

Consejo de Estado. Sala de Consulta y Servicio Civil. Concepto del 14 de septiembre de 2016, rad. 11001-03-06-000-2016-00066-00 (2291). [M.P Edgar González López del 2 de 2016]

Consejo de Estado. Sala plena de lo contencioso Administrativo. Sentencia 2010-00196 del 23 de noviembre de 2010. [M.P Ruth Stella Correa Palacio del 23 de noviembre de 2010]

Garzón, J. (2019). Proceso Contencioso Administrativo. Bogotá, Colombia. Ibáñez.

Kalach Torres, Gina María (2016). Las comisiones de la verdad en Colombia. Revista Jurídica Mario Alario D'Filippo, Vol 8, número 16: 106-124. DOI: https://doi.org/10.32997/2256-2796-vol.8-num.16-2016-1534

Luna Salas, F., y Nisimblat Murillo, N., (2017). El Proceso Monitorio. Una Innovación Judicial Para El Ejercicio De Derechos Crediticios. Revista Jurídica Mario Alario D’Filippo, Vol. 9, número 17: 154-168. DOI: https://doi.org/10.32997/2256-2796-vol.9num.17-2017-1546

Luna Salas, F. (2019). Hechos, Verdad y Prueba. En F. Luna y E. de Río. Compendio de Derecho Probatorio Contemporáneo, p. 39-59. Bogotá, Colombia: Grupo Editorial Ibáñez.

Luna Salas, F. (2019). Técnicas neurocientíficas como medio de prueba pericial. Revista Prolegómenos, Vol. 22, Número 44: 143-154 DOI: https://doi.org/10.18359/prole.4160

Ministerio de salud y protección social. (2020, 12 de marzo). Resolución 385 de 2020.

Presidencia de la República de Colombia. (2020, 17 de marzo). Decreto 417 de 2020.

Presidencia de la República de Colombia. (2020, 6 de mayo). Decreto 637 de 2020.

Presidencia de la República de Colombia. (2009, 23 de diciembre). Decreto 4975 de 2009

Presidencia de la República de Colombia. (2020, 20 de marzo). Decreto 440 de 2020.

Quinche, M. (2018). Derecho constitucional colombiano. Bogotá, Colombia. Temis.

Sánchez Pérez, A. (2020) "La reversión de la potestad reglamentaria en el ordenamiento urbanístico de los municipios en Colombia", Universidad Externado de Colombia, Bogotá, en publicación. 
Safar Díaz, M. (2015) comentario al artículo 185 del CPACA, en: JOSÉ LUIS BENAVIDES (editor), Código de Procedimiento Administrativo y de lo Contencioso Administrativo Ley 1437 de 2011 comentado y concordado.

Viguri Perea, A. y Chiara Marullo, M. (2016) El derecho a un medio ambiente sano y la encrucijada de los alimentos transgénicos. Revista Jurídica Mario Alario D'Filippo, 8 (15): 100-111. DOI: https://doi.org/10.32997/2256-2796-vol.8-num.15-2016-1526 